\title{
A study of annealed GaN grown by molecular beam epitaxy using photoluminescence spectroscopy.
}

\author{
Abigail Bell $^{1,2}$, Ian Harrison', Dimitris Korakakis ${ }^{1,2}$, Eric C. Larkins ${ }^{2}$, J. M. Hayes ${ }^{3}$, \\ M. Kuball ${ }^{3}$. \\ ${ }^{1}$ School of Physics and Astronomy, University of Nottingham, Nottingham, NG7 2RD, \\ UK \\ ${ }^{2}$ School of Electrical and Electronic Engineering, University of Nottingham, Nottingham, \\ NG7 2RD, UK. \\ ${ }^{3}$ H.H.Wills Physics Laboratory, University of Bristol, Bristol, BS8 1TL, UK
}

\begin{abstract}
Photoluminescence (PL) spectroscopy has been used to investigate the effect annealing has on molecular beam epitaxially grown $\mathrm{GaN}$ in different ambients. By observing the changes in the PL spectra as a function of ambient temperature and atmosphere used, important information concerning the origin of defects within $\mathrm{GaN}$ has been found. Samples were annealed in different atmospheres, (including oxygen, oxygen and water vapour, nitrogen and argon), different temperatures. In the $2.0 \mathrm{eV}-2.8 \mathrm{eV}$ region of the PL spectra, two peaks appeared at approximately $2.3 \mathrm{eV}$ and $2.6 \mathrm{eV}$, somewhat higher than the usual yellow luminescence peak. We find that the $2.6 \mathrm{eV}$ peak is dominant for high annealing temperatures and the $2.3 \mathrm{eV}$ peak dominates at low annealing temperatures for the samples annealed in oxygen. When annealed in argon and nitrogen the $2.6 \mathrm{eV}$ peak dominates at all annealing temperatures. Changes in the PL spectra between anneals were also seen in the $3.42 \mathrm{eV}$ region. The $3.42 \mathrm{eV}$ peak is often assigned to excitons bound to stacking faults. Power resolved measurements indicate that in our sample the cause is a donor acceptor pair transition.
\end{abstract}

\section{INTRODUCTION}

Group-III nitrides are direct, wide band gap semiconductors and have many potential uses in optoelectronic devices. The optical and electrical properties of these materials are affected not only by the processes that occur during growth, but also by the post-growth processes that the material undergoes, such as thermal annealing.

Photoluminescence (PL) is used widely to characterise the nitrides. It gives a good indication of the radiative processes that occur within the material. Non-radiative paths reduce the intensity of the PL peaks and so PL is a good indicator of the optical quality of the material. The origins of many of the peaks that commonly occur in $\mathrm{GaN}$ are still not clear. One such peak is the so-called "yellow luminescence" which is a broad peak that appears in the PL spectra at approximately 2.2eV. Ogino and Aoki [1] describe the transition as occurring between a shallow donor $25 \mathrm{meV}$ below the conduction band and an acceptor $860 \mathrm{meV}$ above the valence band. Glaser et al [2] performed PL and optically detected magnetic resonance (ODMR) on GaN layers. They suggested it is a two-part transition in which there is a non-radiative capture between a shallow and deep-donor state followed by a radiative transition between the deep-donor state and a shallow acceptor (possibly $\mathrm{C}$ on a $\mathrm{N}$ site). Ponce et al [3] suggested that the sources of the yellow emission are either dislocations at low angle grain boundaries in the material or point

F99W11.51 
defects, which nucleate at dislocations. It has also been suggested by Reynolds et al [4], that the yellow band in $\mathrm{GaN}$ results from a transition between a shallow donor and a deep level. The deep level in the Reynolds's model was attributed to a complex consisting of a $\mathrm{Ga}$ vacancy and oxygen on a nitrogen site $\left(\mathrm{V}_{\mathrm{Ga}}-\mathrm{O}_{\mathrm{N}}\right)$. Another commonly occurring peak in $\mathrm{GaN}$ is the $3.427 \mathrm{eV}$ peak, seen in the $4 \mathrm{~K}$ PL spectra. It was initially attributed to oxygen forming a shallow "deep level"[5]. However, it has more recently been suggested that peaks in the PL spectra of GaN in this region 3.40eV [6-8], 3.412eV [9] and 3.42eV [10] can be related to excitons bound to stacking faults.

By annealing samples of $\mathrm{GaN}$ in different ambients and at different temperatures, we have clarified some of the issues regarding the role that defects play, particularly in the "yellow luminescence" and the near 3.42eV luminescence regions. GaN samples grown by MBE have been used in this study and annealed at different temperatures in oxygen, oxygen plus water vapour, nitrogen, nitrogen plus water vapour and argon in a high-temperature stage.

\section{EXPERIMENTAL METHOD}

The layer used in this work (sample MG671) was grown by MBE in a modified Varian Mod Gen II machine. The active nitrogen was produced by radio-frequency (RF) plasma source and the $\mathrm{Ga}$ was produced from solid elemental sources. The sample was an unintentionally doped $1 \mu \mathrm{m}$ thick GaN layer grown on a (0001) sapphire substrate. Grown on top of the GaN was a high-mobility field effect transistor (FET) structure consisting of $3 \mathrm{~nm}$ undoped $\mathrm{Al}_{0.15} \mathrm{Ga} 0.85 \mathrm{~N} / 22 \mathrm{~nm}$ Si-doped $\mathrm{Al}_{0.15} \mathrm{Ga}_{0.85} \mathrm{~N} / 15 \mathrm{~nm}$ undoped

$\mathrm{Al}_{0.15} \mathrm{Ga} 0.85 \mathrm{~N}$. Pieces of the sample MG671 were annealed for 20 mins using a high temperature stage at various temperatures and in various gases. The pieces of MG671 were labelled numerically and will be refered to as (number) in the remainder of the paper. The annealing details and sample numbers are shown in table 1.

The photoluminescence spectra were taken using a $325 \mathrm{~nm}$ CW HeCd laser with a maximum excitation intensity of $9 \mathrm{~mW}$. A $325 \mathrm{~nm}$ band pass filter was used to attenuate lines other than the $325 \mathrm{~nm}$ laser line. A quartz lens focused the beam onto the sample in a liquid helium cryostat. The excitation light was normal to the sample and the resulting PL was focused through a low-pass sharp cut-off filter (Oriel WG345), used to stop the laser light, onto the monochromator slit. The $0.75 \mathrm{~m}$ Spex monochromator, with a 2400 lines $/ \mathrm{mm}$ grating, has a resolution of $4 \AA / \mathrm{mm}$, which correspond to $4 \mathrm{meV} / \mathrm{mm}$ in the region

Table 1. Sample numbers with annealing parameters.

\begin{tabular}{|l|l|l|l|l|l|}
\hline Temperature $\left({ }^{\mathrm{O}} \mathrm{C}\right)$ & 800 & 900 & 1000 & 1100 & 1200 \\
\hline $\mathrm{O}_{2}$ & 40 & 41 & 41 & 44 & \\
\hline $\mathrm{O}_{2}$ and $\mathrm{H}_{2} \mathrm{O}$ & & & 63 & & \\
\hline $\mathrm{N}_{2}$ & & & 9 & 46 & 7 \\
\hline $\mathrm{N}_{2}$ and $\mathrm{H}_{2} \mathrm{O}$ & & & 61 & & \\
\hline $\mathrm{Ar}$ & & & 16 & 18 & 19 \\
\hline Pre-annealed & 39 & & & & \\
\hline
\end{tabular}

of $3.4 \mathrm{eV}$. The light was

detected by a bi-alkali photomultiplier (Thorn 9924QB) with a 600V applied voltage. Standard phase sensitive detection techniques were used to improve the signal to noise ratio. 


\section{RESULTS}

In all of the 4K PL spectra (figure 1) there is a peak which occurs in the region from $3.467 \mathrm{eV}$ to $3.479 \mathrm{eV}$ and it has been attributed to the donor bound exciton $\left(\mathrm{D}^{\circ} \mathrm{X}\right)$ [11]. In addition, a peak appears at approximately $3.40 \mathrm{eV}-3.42 \mathrm{eV}$ in all of the spectra. Transitions in this region are commonly attributed to an exciton bound to a stacking fault [6-10]. There is no clear consensus to the exact energy at which this occurs (3.40eV [6-8], $3.412 \mathrm{eV}[9], 3.42 \mathrm{eV}[10])$. From figure 1, the peaks in this area are more pronounced after annealing at higher temperatures $(42,44)$ and in a water vapour atmosphere (63). There also appears to be a correlation between the strain [12], as determined by the position of the $\mathrm{D}^{\circ} \mathrm{X}$ peak and the intensity of the $3.42 \mathrm{eV}$ peak, which could support the stacking fault hypothesis. To investigate this further we have performed power resolved measurements since the excitonic transition should not shift with power. The results are shown in figure 2 for the sample annealed in an atmosphere of $\mathrm{H}_{2} \mathrm{O}$ and $\mathrm{O}_{2}$ (63). In this case the peaks at $3.418 \mathrm{eV}$ and $3.36 \mathrm{eV}$ shift to higher energy with increasing excitation intensity. If the stacking faults act as quantum wells as described in the literature you might also expect to see a blue shift with increasing excitation intensity. However an alternative explanation for the blueshift is that the $3.42 \mathrm{eV}$ peak is a DAP transition[13]. A similar transition has been seen by Eunsoon et al [14]. The samples annealed in $\mathrm{N}_{2}$ and $\mathrm{Ar}$ exhibit a peak in this region which also blueshifts with increasing excitation intensity (not shown here).

Although in the case of the $\mathrm{N}_{2}$ annealed samples, the peak only appears when annealed above $1100^{\circ} \mathrm{C}$.

The $2.0 \mathrm{eV}-2.7 \mathrm{eV}$ region of the PL spectra is considerably altered by annealing

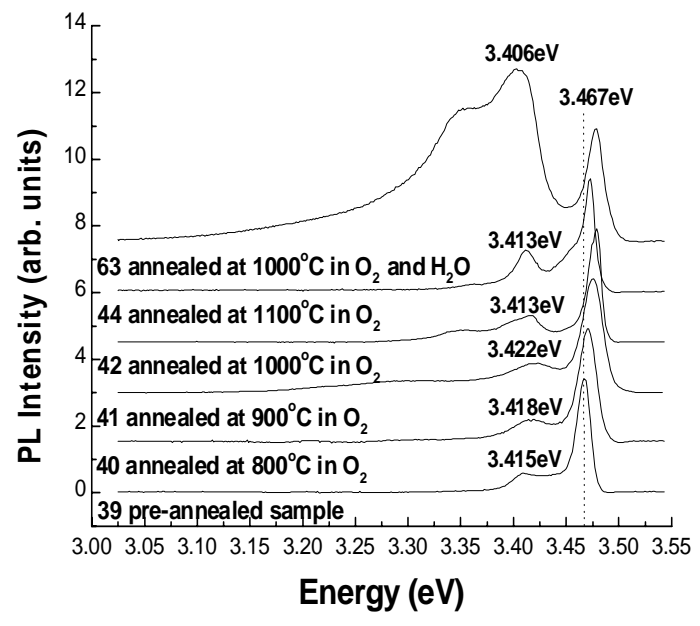

Figure 1. $4 \mathrm{~K}$ PL spectra of sample annealed in $\mathrm{O}_{2}$ and $\mathrm{H}_{2} \mathrm{O}$ at different temperatures. The position of the $D^{\circ} X$ peak shifts from $3.467 \mathrm{eV}$ to higher energy after annealing. the sample. Figure 3 shows the room temperature PL spectra between $2.0 \mathrm{eV}$ $3.1 \mathrm{eV}$ of the pre-annealed (39), annealed in $\mathrm{O}_{2}(40,41$, $42,44)$ and annealed in $\mathrm{O}_{2}$ and $\mathrm{H}_{2} \mathrm{O}(63)$ samples. The pre-annealed sample (39) exhibits only weak PL in this region, with peaks at $2.3 \mathrm{eV}$ and $2.6 \mathrm{eV}$, where the intensity of the $2.6 \mathrm{eV}$ peak dominates. This is at a somewhat higher energy than the usual "yellow luminescence" found in $\mathrm{GaN}$ between 2.0-2.2eV [1-4]. Annealing the samples in $\mathrm{O}_{2}$ greatly enhances the PL intensity at $2.3 \mathrm{eV}$ and $2.6 \mathrm{eV}$, although increasing the annealing temperature to above $1100^{\circ} \mathrm{C}$ causes the $2.6 \mathrm{eV}$ peak intensity to 


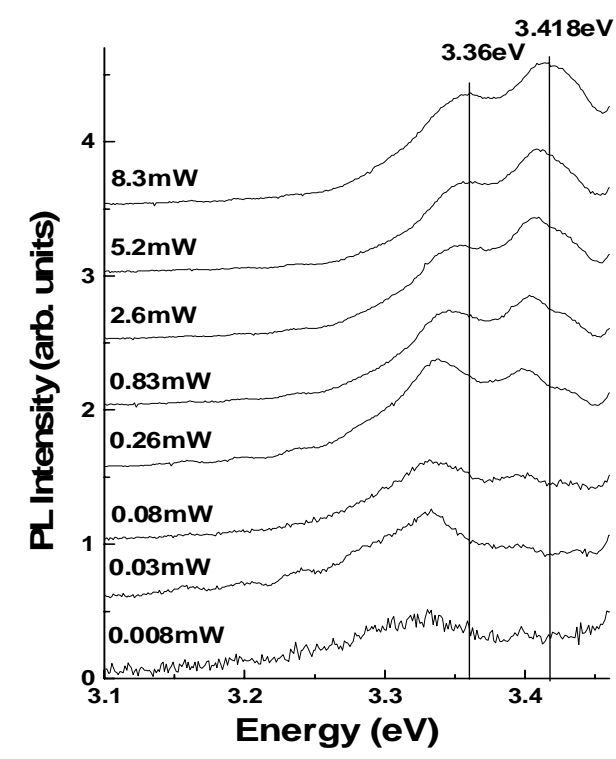

Figure 2. Power resolved PL of sample 63 annealed in $\mathrm{O}_{2}$ and $\mathrm{H}_{2} \mathrm{O}$ at $1000^{\circ} \mathrm{C}$. The $3.418 \mathrm{eV}$ and $3.36 \mathrm{eV}$ peaks shifts with excitation intensity, typical of a DAP transition. The $D^{o} X$ peak, not shown here, is at $3.479 \mathrm{eV}$ and does not shift.

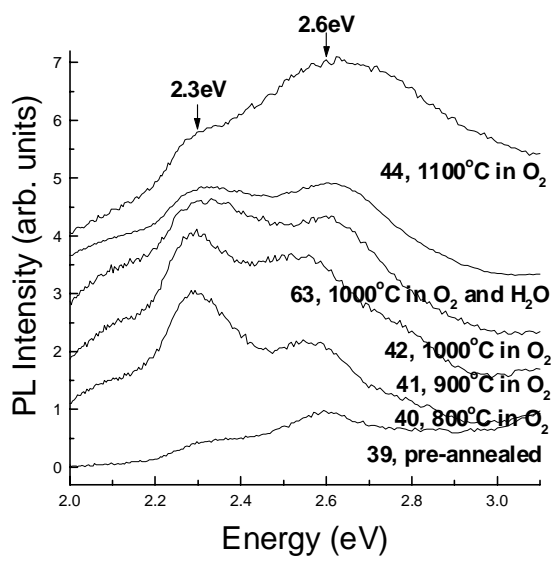

Figure 3. $300 \mathrm{~K}$ PL spectra of samples annealed in $\mathrm{O}_{2}$ or $\mathrm{O}_{2}$ plus $\mathrm{H}_{2} \mathrm{O}$ at different temperatures. Peaks at $2.3 \mathrm{eV}$ and $2.6 \mathrm{eV}$, shown with an arrow, become stronger upon annealing in $\mathrm{O}_{2}$, this effect is even stronger when annealing in $\mathrm{O}_{2}$ and $\mathrm{H}_{2} \mathrm{O}$. become even greater than the $2.3 \mathrm{eV}$ peak. Annealing in both $\mathrm{O}_{2}$ and $\mathrm{H}_{2} \mathrm{O}$ increases the intensity of both the $2.3 \mathrm{eV}$ and $2.6 \mathrm{eV}$ peaks. The two arrows on figure 3 are guides for the eye to the $2.3 \mathrm{eV}$ and 2.6eV PL peaks. Calculations were made and it was found that both the $2.3 \mathrm{eV}$ and $2.6 \mathrm{eV}$ peaks are real PL peaks and not Fabry-Perot thickness oscillations. Similar PL spectra were obtained from the samples annealed in $\mathrm{N}_{2}$ and $\mathrm{Ar}$, although the $2.6 \mathrm{eV}$ peak is dominant (spectra not shown here). The PL intensity in this region in the $\mathrm{N}_{2}$ and $\mathrm{Ar}$ annealed samples also increases with increasing annealing temperature.

Figure 4 shows the power resolved PL of the sample annealed in $\mathrm{O}_{2}$ and $\mathrm{H}_{2} \mathrm{O}(63)$ in the $2.0 \mathrm{eV}$ to $3.1 \mathrm{eV}$ region. The $2.3 \mathrm{eV}$ peak shifts to a higher energy with increasing excitation intensity indicating that it may be DAP type recombination. However, the $2.6 \mathrm{eV}$ peak does not appear to shift over two decades of excitation power and so has free-bound character. The $2.6 \mathrm{eV}$ and $2.3 \mathrm{eV}$ peaks often occur together. If we assume that there is a common defect in these two transitions then we can have two possible situations shown in figure $5 \mathrm{a}$ and $5 \mathrm{~b}$. When the samples were annealed in $\mathrm{O}_{2}$ both peaks increased in intensity. However, when the samples were annealed in $\mathrm{N}_{2}$ and $\mathrm{Ar}$, 


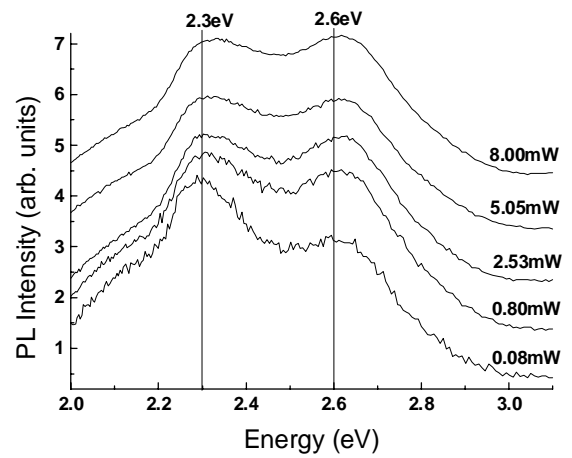

Figure 4. Power resolved PL of sample 63 annealed at $1000^{\circ} \mathrm{C}$ in $\mathrm{O}_{2}$ and $\mathrm{H}_{2} \mathrm{O}$. As the excitation intensity is increased the $2.3 \mathrm{eV}$ peak shifts to a higher energy suggesting a DAP transition. There is no such shift of the $2.6 \mathrm{eV}$ peak.
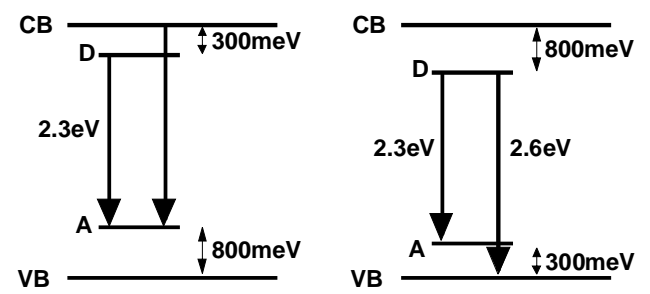

Figure 5(a) A deep acceptor takes part in recombination from an electron on a shallow donor and the conduction band. (b) A deep donor level carries electrons that recombine with both a shallow acceptor level and the valence band. the $2.6 \mathrm{eV}$ peak was dominant suggesting that the annealing process introduces the deep acceptor. The increase in the $2.3 \mathrm{eV}$ DAP transition in the $\mathrm{O}_{2}$ annealed samples provides evidence for the donor at $300 \mathrm{meV}$ being oxygen related. However, it is important to remember that if the model $5 \mathrm{~b}$ had been used, these arguments would point to an oxygen related acceptor. When $\mathrm{H}_{2} \mathrm{O}$ was introduced into the anneal, both peak intensities were increased. This would suggest that the addition of water somehow enhances the introduction of donors (or acceptors) as discussed previously.

\section{CONCLUSIONS}

Annealing the material introduces a defect causing a transition at approximately $3.42 \mathrm{eV}$. A peak appears in this region independent of the annealing atmosphere, although its intensity increases with annealing temperature. If this emission is related to

stacking faults as suggested in the literature [6-10], this would suggest that annealing our material introduces stacking faults and that at higher annealing temperatures, more stacking faults are introduced into the sample. However, an alternative explanation that the $3.42 \mathrm{eV}$ peak is DAP in nature is offered. The increase in the intensity of this line with annealing can then be attributed to the increase in defect (donor or acceptor) concentration.

Deep levels were introduced into the samples by annealing them in various atmospheres. This deep level luminescence consisted of two peaks at $2.3 \mathrm{eV}$ and $2.6 \mathrm{eV}$, which is considerably higher in energy than the usual "yellow luminescence" seen in GaN between $2.0 \mathrm{eV}-2.2 \mathrm{eV}$. In all of the samples, annealing increased the deep level luminescence and increasing the annealing temperature further enhanced the PL intensities. The $2.3 \mathrm{eV}$ peak is a DAP transition, as determined from power resolved PL. The near 
2.6eV peak was dominant in the $\mathrm{Ar}$ and $\mathrm{N}_{2}$ annealed samples. In the samples annealed in oxygen, both peaks competed. suggesting that the $2.3 \mathrm{eV}$ peak is related to oxygen. Two possible models have been suggested and outlined for this luminescence. These models consist of the free-to-bound and DAP transitions being due to either the same donor or acceptor.

\section{ACKNOWLEDGEMENTS}

We would like to acknowledge the EPSRC Blue UV laser diode program and the EU BRITE EURAM MIGHT project No BE98-4899 for part funding on this work. $\mathrm{AB}$ would also like to thank the University of Nottingham for her studentship. The work in Bristol was in part sponsored by Renishaw plc. (Dr. G. D. Pitt)

\section{REFERENCES}

[1] T.Ogino and M.Aoki, Jpn.J.Appl.Phys. 19 p2395 (1980)

[2] E.R.Glaser, T.A.Kennedy, K.Doverspike, L.B.Rowland, D.K.Gaskill, J.A.Freitas Jr, M.Asif Khan, D.T.Olsen, J.N.Kuznia and D.K.Wickenden, Phys.Rev.B 51 p13326 (1995)

[3] F.A.Ponce, D.P.Bour, W.Gotz and P.J.Wright, Appl.Phys.Lett. 68 p57 (1996)

[4] D.C.Reynolds, D.C.Look, B.Jogai, J.E.Van Norstrand, R.Jones and J.Jenny, Solid State Commun., 106 p701 (1998)

[5] B-C Chung and M Gershenzon, J.Appl.Phys. 72 p651 (1992)

[6] M.Albrecht, S.Christiansen, G.Salviati, C.Zanotti-Fregonara, Y.T.Rebane, Y.G.Shreter, M.Mayer, A.Pelzmann, M.Kamp, K.J.Ebeling, M.D.Bremser, R.F.Davis and H.P.Strunk, Mat.Res.Soc.Symp.Proc.Vol.468 p293 (1997)

[7] Y.T.Rebane, Y.G.Shreter, and M.Albrecht, Mat.Res.Soc.Symp.Proc.Vol.468 p179 (1997)

[8] Y.T.Rebane, Y.G.Shreter, and M.Albrecht, phys.stat.sol.(a) 1641411997

[9] S.Fischer, G.Steude, D.M.Hofmann, F.Kurth, F.Anders, M.Topf, B.K.Meyer,

F.Bertram, M.Schmidt, J.Christen, L.Eckey, J.Holst, A.Hoffmann, B.Mensching,

B.Rauschenbach, J.Cryst.Growth 189/190 p556 (1998)

[10] G.Salviati, C.Zanotti-Fregonara, M.Albrecht, S.Christiansen, H.P.Strunk, M.Mayer, A.Pelzmann, M.Kamp, K.J.Ebeling, M.D.Bremser, R.F.Davis, Y.G.Shreter, Inst.Phys.Conf.Ser. 157 p199 (1997)

[11] O.Lagerstedt and B.Monemar, J.Appl.Phys. 45 p2266 (1974)

[12] J.M. Hayes, M. Kuball, A. Bell, I. Harrison, D. Korakakis, and C.T. Foxon, Appl. Phys. Lett. 75 p2097 (1999)

[13] H.B.Bebb and E.W.Williams, Semicond. Semimet., 8 p4-5 (1972)

[14] Eunsoon Oh, Bonjin Kim, Hyeongsoo Park, and Yongjo Park, Appl.Phys.Lett. 73 p1883 (1998) 